\title{
Confronting the Epidemic: The Need for Global Solutions
}

\author{
NEVILLE J. RIGBY, SHIRIKI KUMANYIKA, \\ and W. PHILIP T. JAMES
}

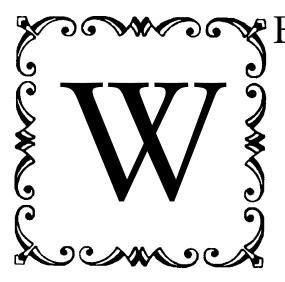

E face a global epidemic of obesity. The World Health

Organization report, Obesity-preventing and managing the global epidemic, first highlighted this as a worldwide problem affecting most countries including those undergoing the "nutrition transition" (I). Subsequent analysis of International Obesity Task Force data suggests around I.I billion people are overweight, including more than 300 million, who are obese (2). However, a new IOTF report to the World Health Organization now recognizes that an additional I 55 million school-age children fall into the overweight and obese category (3). The 'seemingly inexorable rise in mean BMIs,' observed in the WHO Global Burden of Disease Study, reinforces concern that health systems in most parts of the world face overwhelming pressure from diet-induced chronic disease unless effective prevention and treatment strategies are implemented (4).

The falling cost, in real terms, of major food components has resulted in increased consumption of items predominantly based on oils and sugar and other caloric sweeteners. Recognizing this as one of the most readily identified factors underlying global dietary trends, the Food and Agriculture Organization's report World Agriculture: towards $2015 / 2030$ describes, not only a significant increase in energy availability worldwide, but an apparent doubling in energy intake from oils and sugars over the last 30 years. FAO forecasts this to continue to grow until 2030. (see Figures I, 2) Nearly half the additional calories consumed in developing countries by 2030 will derive from oils (5). Globalization of diets, signaling the transition from traditional to processed foods with high energy density, is a key component in the rise of non-communicable diseases (NCDs). 
FIGURE I

Worldwide rise in energy consumption I964-1999

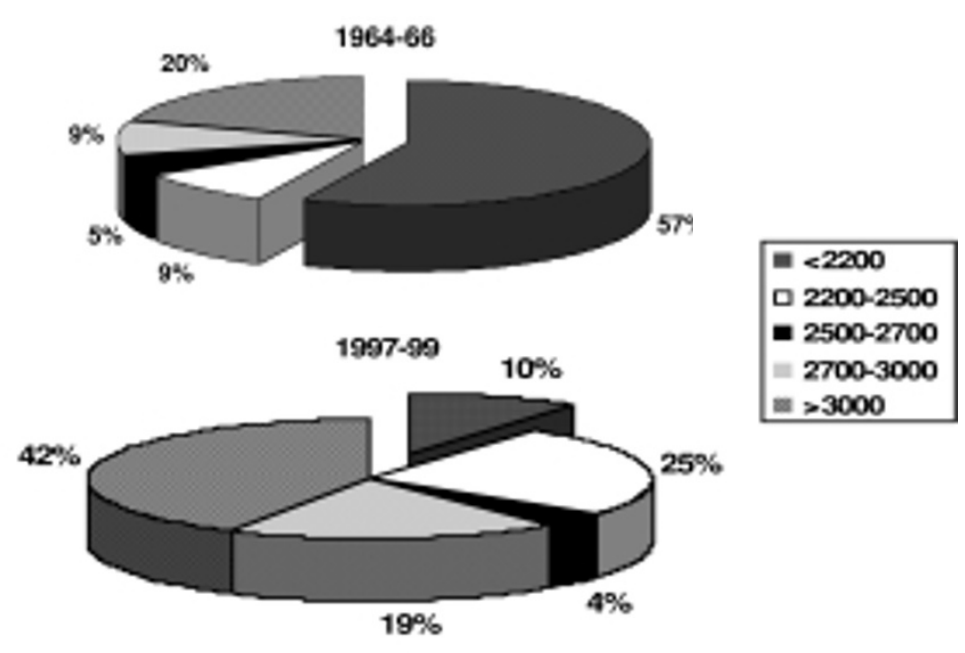

SOURCE: FAO 2002 World Agriculture: Towards 2015/2030.

Because they affect the poorer sections of most populations disproportionately, NCDs can no longer be considered "diseases of affluence." They reflect the influence of an environment in which the impact of urbanization on activity and increased consumption of foods high in fat, sugar, and salt interact, affecting vulnerable populations. In most countries, diabetes, heart disease and certain forms of cancer are now among the principal causes of morbidity and mortality. Diabetes, which already affects the lives of at least I 77 million people, will have twice as many victims by 2030 (6). Heart disease already accounts for I 6.6 million deaths-one third of all deaths globally; around $80 \%$ occur in low- and middle-income countries (7).

While under nutrition remains an unsolved challenge, largely due to political instability and inappropriate development policies, some countries in Asia, Africa, the Middle East and Latin America now experience a "double burden" of nutritional disease (8). Complex nutritional factors affecting fetal development and early life predispose certain populations to greater health risks with only modest weight gains. A history of subsistence and deprivation, reflected in poor nutrition during pregnancy and consequent low birth weights, seems to 
FIGURE 2

Forecast rise in food consumption in developing countries to 2030

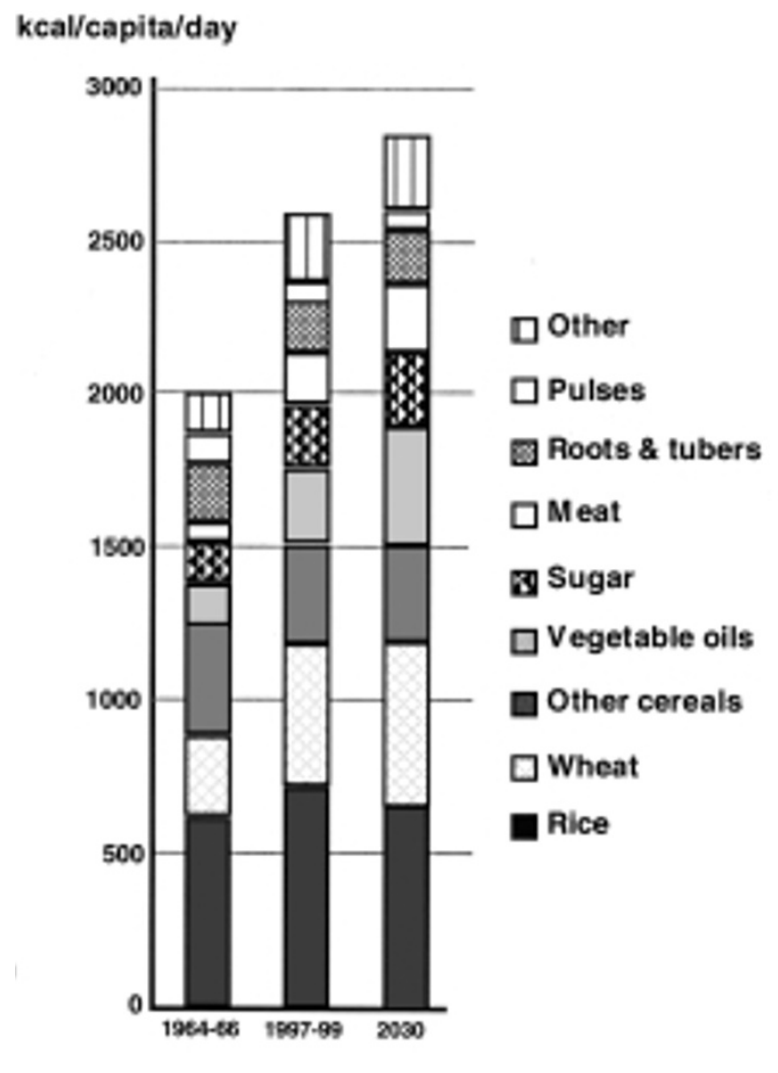

SOURCE: FAO 2002 World Agriculture: Towards 201 5/2030.

make some populations particularly vulnerable to visceral obesitythe selective deposition of fat in the abdomen-markedly increasing the risks of the metabolic syndrome. People with metabolic syndrome are overweight, and present with insulin resistance, abdominal fat, high blood sugar and triglycerides, low levels of high-density lipoprotein cholesterol, and high blood pressure (9).

The prevalence of the metabolic syndrome helps explain the need for comprehensive measures aimed at the whole population to control the obesity epidemic. The numbers affected by metabolic syndrome worldwide have yet to be determined. Given the recent confirmation 
by a WHO expert group of increased exposure to metabolic risk factors among diverse Asian populations at lower BMI levels, IOTF estimates suggest that overall up to I.7 billion people worldwide may face elevated risks due to raised body fat levels (IO). The rapid increase in the number of overweight children with type 2 diabetes and metabolic syndrome risks has yet to be factored into any assessment (I I). Because individual children cannot be held responsible, pediatric overweight challenges us to devise new solutions to combat chronic noncommunicable diseases throughout the world. Clearly major preventive initiatives are the only feasible policy option.

The prognosis for this epidemic may be far worse than could have been previously imagined. Described as a public health time bomb, the implications of rising childhood overweight, with new evidence that the prevalence of metabolic syndrome is high among overweight children, reinforces warnings from senior medical and public health officers that some of the youngsters-afflicted with blindness, kidney failure, and certainly facing reduced life expectancy-may not outlive their parents (I2).

\section{PREVALENCE}

In many countries more than half the adult population is overweight. Countries such as the United Kingdom, Finland, Germany and many East European countries have obesity rates in excess of $20 \%$ of adults; in some, the prevalence has doubled or even trebled in less than two decades. Even higher prevalences are found in some North African and Middle East countries, particularly the Gulf States (I3). As obesity rates escalate, the emergence of extreme or "morbid" obesity accelerates even faster. Prevalence in the United States has risen steadily, affecting almost $3 \mathrm{I} \%$ of all adults, but in the group most severely affected, black American women, almost half are obese, and around I $5 \%$ have a $\mathrm{BMI} \geq 40$. These women are thus eligible for surgical intervention due to morbid obesity (I4).

In the developing world, high rates of obesity are also found and few areas are immune as shown in Figures 3 and 4 (I 5 ). Obesity reaches its highest level on several Pacific islands where an adult prevalence of $60-80 \%$ has been reported and some of the highest levels of diabetes are also to be found. South Africa has undertaken large demographic surveys of similar quality to the NHANES surveys in the US and found high rates of overweight and obesity. Women had a mean BMI 
FIGURE 3

Adult male obesity prevalence collated from available data

Clobal prevalence of obesity (EMI >10) in males

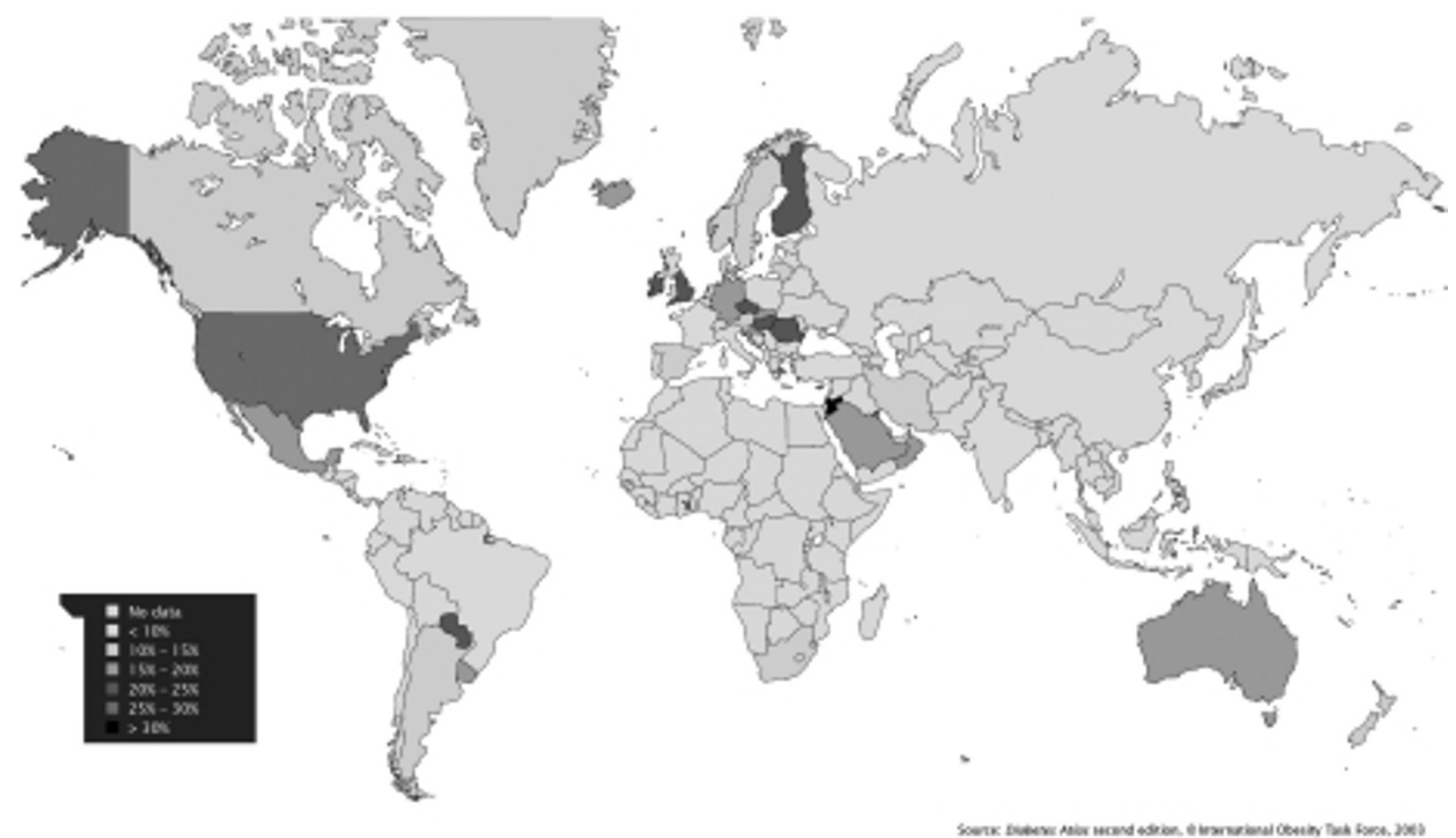

Source: IOTF database/International Diabetes Federation Atlas of Diabetes 2003. 
FIGURE 4

Adult female obesity prevalence collated from available data

Clobal prevalence of obesity (EMI 230 ) in females

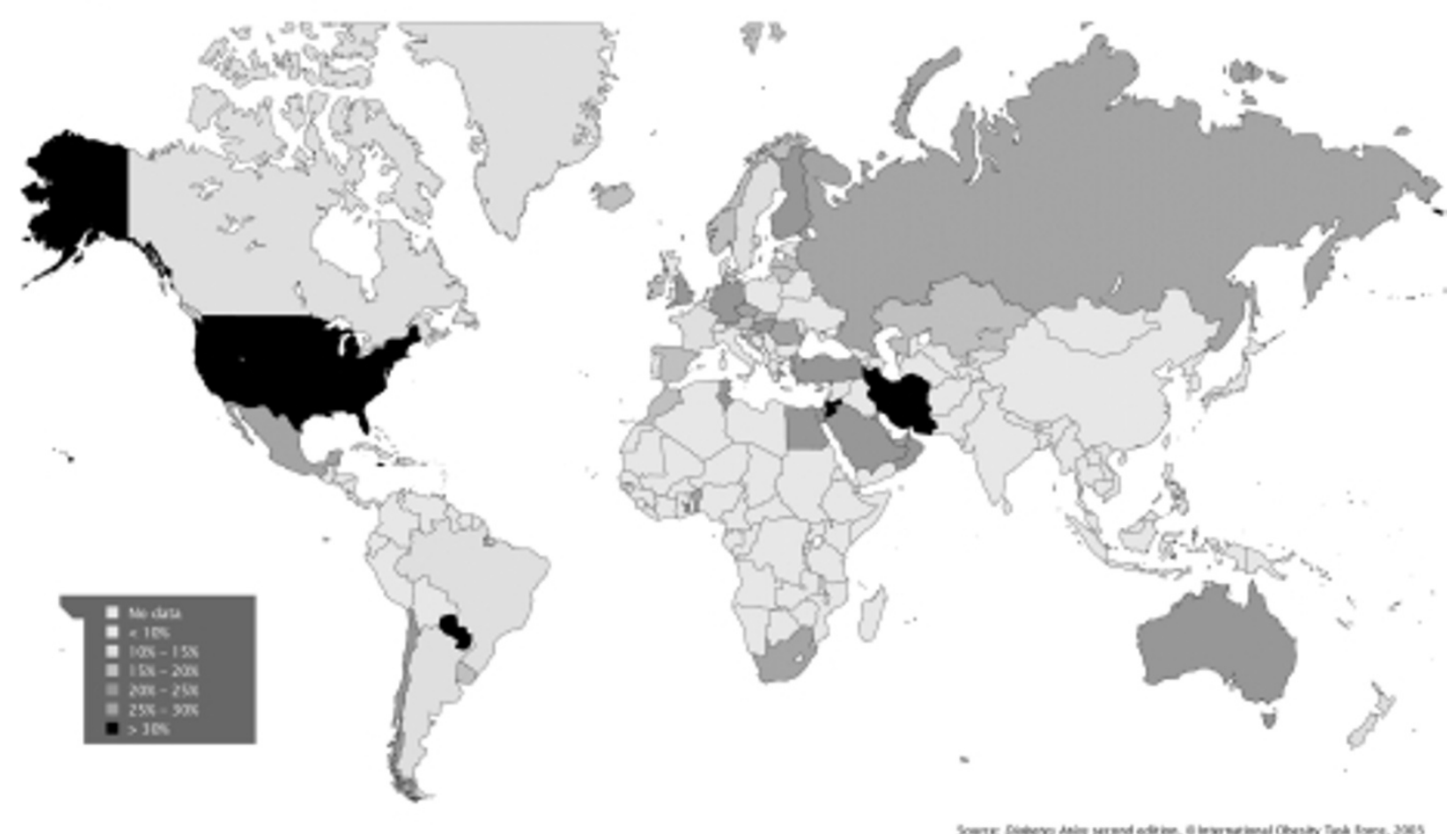

SOURCE: IOTF database/International Diabetes Federation Atlas of Diabetes 2003. 
of 27 and $29 \%$ of them were obese (BMI $\geq 30$ ). The 1998 South African Demographic and Health Study (SADHS) also found $9.2 \%$ of men had abdominal obesity, whereas $42 \%$ of women were similarly affected. Underweight, using the WHO definition of BMI<I 8.5, affected $12.2 \%$ of men and $5.6 \%$ of women (I6). More recent data, compared with IOTF international reference points for childhood obesity, show overweight among South African youngsters aged I3-I9 years affected $7 \%$ of boys but $25 \%$ of girls. Kwa-Zulu Natal had the highest provincial rate, almost $23 \%$ overall ( 17 ).

Overweight and obesity are increasing rapidly among children in many parts of the world. In Europe, rates of obesity are escalating, with up to $36 \%$ affected in some southern Mediterranean regions (I 8) where previously obesity was rare. Recent emergence of type 2 diabetes among children and adolescents, almost non-existent little more than a generation ago, indicates the gravity of the childhood obesity crisis which is now widespread (IO). A mass screening program of Taiwanese children identified a 6:I ratio of type 2 to type I diabetes, with obesity as the major risk factor for the development of type 2 diabetes. The likelihood of having type 2 diabetes in obese children (above the 95th percentile ranking for their age and sex) was I 8.8 times greater than those on the median or 5 oth percentile (I9).

THE METABOLIC SYNDROME

Forty-seven million US adults are affected by metabolic syndrome. NHANES data from the early I990s showed this cluster of risk factors to affect 9I0,000 youngsters aged I $2-19$, or $4.2 \%$ of all US teenagers. The syndrome was present in $28.7 \%$ of adolescents termed "overweight" (defined as above the 95 th percentile) - four times the $6.8 \%$ level found in "at-risk" adolescents (defined as above the 85 th percentile) (20).

The impetus behind the epidemic of weight gain and the development of the metabolic syndrome is a diet dominated by sweetened beverages, energy-dense foods, high in fat and sugars. Unnecessary addition of salt not only compounds weight-induced hypertension, but also amplifies thirst, probably encouraging further drinking of sugary beverages. Fruits and vegetables consumption is insufficient and there are reduced levels of physical activity. Governments have documented the dietary trends and associated obesity rates, but largely failed to recognize the profound consequences for public health. US 
Department of Agriculture analyses show that the consumption of added oils in the American diet has risen by two-thirds, with a per capita intake of $74.5 \mathrm{lb}$ per annum in 2000 compared to $44.6 \mathrm{lb}$ per annum in the I950s. The average American also consumed an additional $43 \mathrm{lbs}$ of added sugars and sweeteners in 2000, compared to the I950s. According to USDA figures, Americans now consume on average $530 \mathrm{k}$-calories more every day than they did 30 years ago. They are probably less active, given the pervasive car economy, labor saving devices, and computer-based environment (2I).

Profiling Food Consumption in America, (USDA Agriculture Factbook 200I-2002) tells us that "USDA recommends that the average person on a 2,000-calorie daily diet includes no more than 40 grams of added sugars. That's about Io teaspoons, or the amount of sugar in a I 2-ounce soft drink. Sugar including sucrose, corn sweeteners, honey, maple syrup, and molasses-is ubiquitous and often hidden. In a sense, sugar is the number one food additive. It turns up in some unlikely places, such as pizza, bread, hot dogs, boxed mixed rice, soup, crackers, spaghetti sauce, lunchmeat, canned vegetables, fruit drinks, flavored yogurt, ketchup, salad dressing, mayonnaise, and some peanut butter. Carbonated sodas provided more than a fifth ( 22 percent) of the refined and added sugars in the 2000 American food supply, compared with 16 percent in I970.”

\section{POLICY PARADOX}

Despite official government recommendations to control energy intake and particularly to limit added sugars, governments support sugar producers and processors. Public subsidies in the US and EU have ultimately fuelled the manufacture of ever more, and less expensive fat and sugar-based snacks and drinks. These components of the dysfunctional diet-the typical American diet-have been rapidly exported to the wider world, compounded by equally rapid urbanization which has led to predominantly sedentary lifestyles and severely reduced opportunities for physical activity (22). Characterized by Brownell as a "toxic environment" that overwhelms the personal resources of individuals, the economic drivers generating this environment are now universal (23). Chopra and others have noted: "In the USA, I70,000 fast food restaurants and three million soft drink vending machines have changed the country's eating patterns. The same thing is happening in other countries to a greater or lesser degree" $(24)$. 
The problem is by no means confined to the US and investment analyses of Eastern Europe and the developing world show that apart from armament and tobacco sales, industrial conglomerates from the USA, UK, and Western Europe are heavily investing in confectionery, fast food and soft drink manufacturing and retailing (25).

Trade impacts health. In the Pacific islands, some governments, including Fiji and Tonga, given the high levels of obesity and related chronic diseases suffered by their populations, tried to halt the import of "mutton flaps" - fat from sheep. They faced new resistance-implied threats to use the World Trade Organization system to enforce continued importation, despite adverse health consequences.

A WHO Bulletin article illustrates the difficulties in changing attitudes: "Given recent initiatives towards trade liberalization and the creation of the World Trade Organization, tariffs or import bans may not serve as alternative measures to control consumption. This presents significant challenges to health policy-makers serving economically marginal populations and suggests that some population health concerns cannot be adequately addressed without awareness of the effects of global trade" (26). The costs to human health ought to spur governments to introduce health impact assessments on trade arrangements and to use powers so far reserved largely for acute food safety issues to restrict trade where goods can be demonstrated to have deleterious effects. A subsequent meeting of health ministers in Tonga noted:

Political will is central to the whole process of NCD control. Too often, sectors outside health value other aspects of socio-economic development above health. Such political will can be expressed in various ways: through making diabetes a priority disease in national planning, and through innovative legislation such as banning mutton flap importation and tobacco control through legislation. Politicians themselves have to be role models to promote bealthy behaviors. (27)

\section{ECONOMIC COSTS}

The costs of obesity and its co-morbidities are routinely underestimated. Crude estimates of costs amount to $7 \%$ of total health care budgets in some countries ( 5 ). In England, the National Audit Office has estimated annual costs of $\$ 5.4$ billion (28). Other recent estimates of the overall cost of diet-related disease to the National Health Service were as high as \$27 billion (29). Prior to European Union enlargement, the 
cost of overweight and obesity was estimated at between \$90-I 56 billion in I 5 member states (30). This appears not dissimilar to estimates for the US, where medical costs were estimated to be $\$ 75$ billion in 2003 (3 I). With direct and indirect costs combined, obesity has been estimated to cost the US as much as \$ 23 billion each year (32).

\section{SUPPORTING STRATEGIES FOR CHANGE}

Representatives of 192 member nations of the World Health Assembly agreed in May to adopt the WHO's global strategy on diet, physical activity, and health. Ministers gave their approval despite an intense lobbying, particularly by the sugar industry, which claimed the broad support of the food and drinks sectors. The strategy emphasizes the need for coherent action at national levels to address nutritional health, including the prevention of obesity and concomitant non-communicable diseases.

The IOTF encourages the development of comprehensive government strategies to engage all levels of society in addressing the problem of overweight and obesity. The IOTF supports the WHO report, Diet, Nutrition and the Prevention of Chronic Diseases (WHO TRS 9I6) that outlined a range of common options that governments may consider to tackle the obesity epidemic (20).

Some specific measures proposed in the $\mathrm{WHO}$ "916" report encountered predictable resistance from commercial interests, some of whom have subsequently sought to reposition their companies as "part of the solution." The WHO population nutrient goal, to limit added sugars to no more than Io\% of energy intake (broadly in line with the USDA recommendation), provoked a hostile reaction from parts of the sugar industry itself and from sugar producing countries. These countries had been misled into fearing adverse economic consequences from health recommendations for sugar. These have stood as WHO recommendations since $\mathrm{I} 990$ and exist as standards in many countries. The Global Strategy itself recommends governments consider limiting added sugars. The Strategy also suggests that governments may consider what measures may be needed to protect children from intensive marketing of high-energy dense foods or may consider how fiscal measures may be used. Despite the reservations of some, two major trade organizations-the Grocery Manufacturers of America and its European counterpart, the CIAA, issued statements broadly welcoming the global strategy (33). 
Increasing consumption of foods high in fats and sugars must be addressed if there is to be any prospect of arresting the escalation of the obesity epidemic, let alone achieve any reduction in the high prevalence levels. This challenge requires a new level of responsibility from the food industry to change the content of food products, the proportions of those products, and the intensity of promotion of food products, particularly to vulnerable consumers, whether children or adults.

\section{ARE SMALL STEPS ENOUGH?}

Public health policy in many countries is being drawn towards an emphasis on physical activity as a "balance" to over-consumption. Campaigns, supported by major food brands, imply it is the individual's responsibility to be more energetic, to burn off excess calories. They reject the idea that the responsibility to work towards improved nutritional quality and balance is shared by food producers, manufacturers, and suppliers. Some campaign recommendations imply that very low levels of activity or calorie reduction are sufficient to resolve overweight. This may well mislead people into adopting activity levels that convey few real benefits in dealing with weight.

The level of physical activity required for weight maintenance has been reviewed by the IOTF and International Association for the Study of Obesity (IASO) experts as well as the US National Academy of Sciences and the American College of Sports Medicine. All agree that a greater level of activity than commonly recommended is needed to address weight maintenance, let alone reduce weight.

An IASO consensus meeting of physical activity experts suggested that 30 minutes daily activity, whilst of importance in limiting other health risks, was likely to be insufficient to prevent weight gain "in the current environment." The subsequent consensus statement suggested: "There is compelling evidence that prevention of weight regain in formerly obese individuals requires 60-90 minutes of moderate intensity activity or lesser amounts of vigorous intensity activity. Although definitive data are lacking, it seems likely that moderate intensity activity of approximately 45 to 60 minutes per day, or I.7 PAL is required to prevent the transition to overweight or obesity. For children, even more activity time is recommended" (34).

The NAS recommendation was equally clear. "Thirty minutes per day of regular activity is insufficient to maintain body weight in adults in the recommended body mass index range from I 8.5 up to $25 \mathrm{~kg} / \mathrm{m} 2$ and achieve all the identified health benefits fully. Hence to prevent 
weight gain as well as accrue additional, weight-independent health benefits of physical activity, 60 minutes of daily moderate intensity physical activity (e.g. walking/jogging at 4 to $5 \mathrm{mph}$ ) is recommended in addition to the activities required by a sedentary lifestyle."

To emphasize the importance of both diet and physical activity, the American College of Sports Medicine issued a position statement: "Physical exercise alone without dieting (caloric restriction) has only a modest effect on total body mass and FM loss. Caloric restriction generally produces the most substantial weight losses compared with exercise alone simply because it is easier to induce a marked energy deficit by the former."

Some companies, particularly those who fear legal action on obesity, view support for physical activity as a valuable component of the corporate social responsibility strategies. But it also sells their products. They support sports, gaining a 'virtuous' association of a high sugar drink brand or a high energy density food with sporting heroes.

Major international food and drink corporations are beginning to take note of the limited legal actions already mounted against food companies, whether successful or not. [A German judge brought one of the first cases against Masterfoods.] He claimed modest damages of $\$ 5,000$, attributing his type 2 diabetes to consumption of the company's confectionery. While his case failed, it nevertheless heralded a new era in legal approaches to food and health liabilities. In Brazil Ambev-Pepsi and Coca Cola face a continuing state-backed legal process over marketing to children.

Perhaps the most significant consequence of early lawsuits in the US has been reviews by international fund holders, assessing the "health risk" of holding major investments in the exposed snack food and beverage sectors. The European office of JP Morgan, and others, have drawn clear conclusions that there are risks of holding funds. This has probably done more to focus minds in the corporate food sector than the WHO dialogue which first challenged companies to become "part of the solution" (35).

Addressing responsibility, rather than blame, presents a more effective approach to involving everyone in tackling the obesity epidemic. No longer can we afford to disregard the wider societal responsibility to care for the health of children whilst excusing inaction by shifting the onus to individuals. This "personal responsibility" approach has been tested over many decades and as a public health policy has clearly failed. Equally there is no evidence to support a presumption that 
health goals can be attained by being subordinated to a "free market" in which consumer choice is dominated by skewed marketing priorities favoring energy dense foods of low nutritional value. Societal controls are recognized as valid and desirable in many areas of health, including tobacco, where a free market continues to inflict permanent harm on consumers and non-consumers alike. This approach has recently been emphasized by a leading British banker in his report to the UK Chancellor of the Exchequer, which highlights the fundamental need for an economic approach to these health issues and a restructuring of economic and other societal regulations (36).

\section{CONCLUSION}

Global populations will continue to become progressively heavier if present consumption forecasts are sustained. The resultant increase in diet-induced obesity, diabetes, and cardiovascular disease and a full range of co-morbidities implies a burden of social and economic costs that no country, least of all developing countries with limited resources, can afford. A fundamental re-orientation of not only public health policies, but of all contingent policies is needed to reflect a shared responsibility among many stakeholders to work towards improving the quality of diet and activity for whole populations in order to minimize weight-related ill health. This requires real commitments and effective action from non-health sectors such as culture and education, commerce and trade, development, planning, and transport. Only a comprehensive and integrated international approach, based on an effective implementation of the WHO global strategy on diet, physical activity and health, offers any real hope of arresting the public health catastrophe unfolding throughout the world (37).

\section{REFERENCES}

I. World Health Organization TRS 894: Obesity: preventing and managing the global epidemic [monograph on the Internet]. Geneva; WHO, 2000 [cited 2004 June Io]. Available from: http://whqlibdoc.who.int/trs/WHO_ TRS_894.pdf

2. IOTF global database: Analysis from data collated for WHO global burden of disease study [database on the Internet]. London: IOTF. c2004 [cited 2004 June I $_{5}$ ]. Available from: www.iotf.org/database 
3. Lobstein T, Baur L, Uauy R. Obesity in children and young people. A crisis in public health; an IOTF report to WHO. Obesity Reviews. 2004 May; 5 (sI): 4 .

4. James WPT, Jackson-Leach R, Mhurchu C, Kalamara E, Shayeghi M, Rigby NJ, et al. Overweight and Obesity (high body mass index). In Global Burden of Disease. Cambridge, MA: WHO/Harvard University Press, 2004. Chapter 8.

5. World agriculture: towards $2015 / 2030-A n$ FAO Perspective [monograph on the Internet]. Rome: FAO/Earthscan; 2003 [cited 2004 June 20]. Available from: http://www.fao.org/docrep/o05/y4252e/y42 52 eoo.htm

6. World Health Organization [homepage on the Internet]. Geneva: WHO; c2004 [cited 2004 June I 5]. World Health Organization Diabetes Database [several pages]. Available from: http://www.who.int/diabetes/databases.htm

7. World Health Report 2002 [monograph on the Internet]. Geneva: WHO; 2002 [cited 2004 June I6]. Available from: http://www.who.int/whr/ 2002/en/

8. James WPT, Norum K, Smitasiri S, Swaminathan MS, Tagwireyi J, Uauy R, et al. Ending Malnutrition by 2020: an Agenda for Change in the Millennium: Final Report to the ACC/SCN by the Commission on the Nutrition Challenges of the 2ist Century. Supplement to the Food and Nutrition Bulletin. 2000 September/October.

9. Third Report of the National Cholesterol Education Program (NCEP) Expert Panel on Detection, Evaluation, and Treatment of High Blood Cholesterol in Adults (ATPIII), 200I.

ıо. WHO Expert Consultation. Appropriate body-mass index for Asian populations and its implications for policy and intervention strategies. The Lancet. 2004 January 10;363 (9403): 1 57-63.

I r. Ebbeling C, Pawlak D , Ludwig D. Childhood obesity: public-health crisis, common sense cure. The Lancet. 2002 August I0;360(933 I):473-82.

I2. Weiss R, Dziura J, Burgert TS, Tamborlane WV, Taksali SE, Yeckel CW, et al. Obesity and the Metabolic Syndrome in Children and Adolescents NEJM. 2004 June 3;350(23):2362-2374.

I3. IOTF Global Database [database on the Internet]. London: IOTF. c2004 [cited 2004 June I 5]. Available from: www.iotf.org/database

I4. Hedley AA, Ogden CL, Johnson CL, Carroll MD, Curtin LR, Flegal KM. Prevalence of Overweight and Obesity Among US Children, Adolescents, and Adults, I999-2002. JAMA. 2004 June I6;29I:2847-2850.

I 5. IDF Atlas of Diabetes 2003 / IOTF Database [database on the Internet]. London: IOTF. c2004 [cited 2004 June I 5]. Available from: www.iotf.org/ database

I6. Department of Health, South Africa [homepage on the Internet]. Cape Town: DOHZA; c2004 [cited 2004 June 20]. South African Demo- 
graphic and Health Study (SADHS) I 998 [many pages]. Available from: http://www.doh.gov.za/facts/I998/sadhs98/

I7. Reddy SP, Panday S, Swart D, Jinabhai CC, Amosun SL, James S, et al. The First South African National Youth Risk Assessment Survey 2002 [monograph on the Internet]. Cape Town: South African Medical Research Council; 2003 [cited 2004 July 20]. Available from: www.nyc.gov.za/docu ments/research/youth_risk_behave_survey_2002.pdf

I8. IOTF. Position paper Obesity in Europe 2. EUItaly 2003: Proceedings of the EU ministerial conference on health promotion; 2003 September 2-3; Milan, Italy. For more information on the conference see: http://tinyurl.com $16 \mathrm{ok}_{3} \mathrm{~b}$

I9. Wei JN, Sung FC, Lin CC, Lin RS, Chiang CC, Chuang LM. National Surveillance for Type 2 Diabetes Mellitus in Taiwanese Children. JAMA. 2003 September IO;290(I0):I345-I350.

20. Cook S, Weitzman M, Auinger P, Nguyen M, Dietz WH. Prevalence of a metabolic syndrome phenotype in adolescents: findings from the third National Health and Nutrition Examination Survey, I988-1994. Arch Pediatr Adolesc Med. 2003 Aug; I 57(8):82 I-7.

2I. United States Department of Agriculture Office of Communications. USDA Agriculture Factbook 200I-2002. Washington, DC: USDA; 2002. Also available from: http://www.usda.gov/factbook/

22. WHO TRS 9i 6: Diet, Nutrition and the Prevention of Chronic Diseases [monograph on the Internet]. Geneva/Rome: WHO; 2003 [cited 2004 June I 5]. Available from: http://whqlibdoc.who.int/trs/WHO_TRS_9 I6.pdf

23. Brownell KD, Horgan KB. Food Fight. New York: Contemporary Books; 2004.

24. Chopra M, Galbraith S, Darnton-Hill I. A global response to a global problem: the epidemic of overnutrition. Bulletin of the World Health Organization 2002;80(I2).

25. Broadcasting Bad Health: Why food marketing to children needs to be controlled [monograph on the Internet]. London: International Association of Consumer Food Organizations; 2003 [cited 2004 June 20]. Available from: www.foodcomm.org.uk/Broadcasting_bad_health.pdf

26. Evans M, Sinclair RC, Fusimalohi C, Viliami L. Globalization, Diet, And Health: An Example From Tonga. Bull World Health Organ. 200I;79(9): $856-862$.

27. World Health Organization Regional Office For The Western Pacific Region Report. Proceedings of Meeting Of Ministers Of Health For The Pacific Island Countries; 2003 March 9-I3; Nuku'alofa, Tonga. Manila, Philippines, WHO Regional Office; 2003.

28. National Audit Office. Tackling Obesity in England [monograph on the Internet]. London: The Stationary Office; 200I [cited 2004 June Io]. Avail- 
able from: http://www.nao.org.uk/publications/nao_reports/oo-oI/ooo I 220.pdf

29. Fairweather-Tait SJ. Human nutrition and food research: opportunities and challenges in the post-genomic era. Philos Trans R Soc Lond B Biol Sci. 2003 October 29;358(I438):I709-27.

30. Rayner G, Rayner M. Fat is an Economic Issue! Combating Chronic Diseases in Europe. Eurohealth. 2003 Spring;9(I):I7-2O.

3I. Finkelstein EA, Fiebelkorn IC, Wang G. State-Level Estimates of Annual Medical Expenditures Attributable to Obesity. Obes Research. 2004; I 2: I 8-24.

32. Wolf, AM, Manson JE, Colditz GA. The Economic Impact of Overweight, Obesity and Weight Loss. Eckel R, editor. Obesity. Philadelphia: Lippincott, Williams and Wilkins; 2002.

33. Statement by the Grocery Manufacturers of America and the Confèdèration des Industries Agro-Alimentaires de l'UE/ Confederation of the Food and Drink Industries of the EU (CIAA) during the WHO Executive Board Sessions, January 2004.

34. Saris WH, Blair SN, van Baak MA, Eaton SB, Davies PS, Di Pietro L, et al. How much physical activity is enough to prevent unhealthy weight gain? Outcome of the IASO ist Stock Conference and Consensus Statement. Obes Rev. 2003 May;4(2):IOI-I4.

35. Food Manufacturing Obesity: The big issue. London/Geneva: JP Morgan European Equity Research London/Geneva; 2003.

36. Wanless D. Securing Good Health for the Whole Population. HM Treasury Independent Review. London: HM Treasury, 2004. Also available from: http://tinyurl.com/54gbs

37. Health Promotion and Healthy Lifestyles. World Health Organization Executive Board Resolution EEBII3/7; 2003 November 27; Geneva: WHO; 2004. Available from: http://www.who.int/gb/ebwha/pdf_files/ EBI I3/eeb I I37.pdf

\section{SUMMARY}

The growth in the global epidemic of obesity is fundamentally linked to economic factors. The rising prevalence of overweight and obesity has occurred during a period when the real cost of the main components of many processed foods has declined significantly, partly due to state subsidies in the protected markets of western economies. It is suggested that the vigorous promotion of foods high in fats and sugars, and intensive marketing to children, have aggravated the problems of obesity. The metabolic syndrome, a recent feature of the epidemic, now is a marker for the health impact of obe- 
434 SPECIAL SECTION: APPROACHES TO THE OBESITY EPIDEMIC

sity both in the US and other countries. The IOTF suggests that global populations will continue to become progressively heavier if present consumption forecasts are sustained, with obesity imposing a burden of social and economic costs that no country, least of all developing countries with limited resources, can afford. Commitments to deliver effective action are needed from non-health sectors such as culture and education, commerce and trade, development, planning, and transport. Only a comprehensive and integrated international approach, based on an effective implementation of the WHO global strategy on diet, physical activity and health, offers any real hope of arresting the public health catastrophe unfolding throughout the world. 